\title{
Cross-national analysis of the older workers' employment rate
}

\author{
Oleh $\mathrm{Kratt}^{1}$, Inna $\mathrm{Kirnos}^{1 *}$ \\ ${ }^{1}$ Kremenchuk Mykhailo Ostrohradskyi National University, Pershotravneva Street 20, 39600 \\ Kremenchuk, Ukraine
}

\begin{abstract}
The share of older people in population structure is constantly rising in developed countries. This leads to a decrease of working age population. Labor market situation of Eastern European countries is aggravated by labor force migration. An effective response to challenges of ageing is productive ageing policy aimed at attracting older workers to labor market. The countries with remarkable success in older workers' employment are defined in the article. Research method - analysis of extreme values repeatability ( 5 leading countries and 5 outsider ones) of the statistical sample. An object of the study - is replenishment of human resources at the national labor market. Subject of the study is involving older workers to national labor market. There are three stages of the study. The first stage is ranking the countries according to the older workers' capability to implement their professional qualities at the labor market on a global scale. Capability domain of Global Age Watch Index is chosen as a criterion for ranking. Relative stability (the composition of countries) and relative volatility (annual change of country indicators' value) are the features of the leaders' group. The main feature of the outsider's group is absence of the state policy towards older workers' employment. The second stage of the study is ranking OECD countries by older workers' employment rate. PWC Golden Age Index. Is chosen as a criterion of ranking The values of the criterion is a result of the common policy in the framework of intergovernmental agreements. The proof is positive dynamics of the criterion in both groups. The third stage of study is ranking European countries by duration of the working life. State policy of productive ageing is directed towards prolongation of working life. So, direction of seniority duration characterizes policy effectiveness. Extreme values of seniority demonstrate mutual loyalty of the employers and employees. The decrease in the highest values of seniority and the suspension of their pace of dynamics suggests the existence of an upper limit of seniority. The growth rate of low values of seniority is increasing, which proves the mobility of the bottom line.
\end{abstract}

Key words: Global Age Watch Index, Golden Age Index, older people, ranking, productive ageing policy, labor market, duration of working life

*Corresponding author: innakirnos1976@gmail.com 


\section{Introduction}

The share of older people in the population is increasing in the majority of countries. Decline in fertility rates and increased life expectancy are causing a significant shift in the global age structure. The ageing of the world's population introduces several major policy challenges, and its unprecedented nature means that we cannot look to earlier historical episodes for guidance on how this demographic upheaval will unfold or on how best to manage it [1]. Social structures developed in the times of growing population should be revisited in times of global ageing.

Declining and aging populations are often viewed as having negative effects on economic growth and employment. Decreasing share of younger people in a population is perceived as leading to a reduction in economic activity, whereas an increase in the proportion of older people is perceived as resulting in an economic burden due to higher requirement for pensions and health care. Most industrialized countries will experience a rapid shift towards increased elderly dependency ratios over the coming decades [2]. The growing number of retirees and shrinking labor force threatens the sustainability of the welfare systems, while the increase in life expectancy makes pensions expensive. Many countries have therefore implemented reforms that improve the financial sustainability of public pension programs by increasing the public pension age [3].

Europe is one of the world's oldest populations. Many European states have the lowest fertility rates and highest life expectancy rates in the world. Much of the focus of policy action has been on old-age pension reform but a more comprehensive set of reform may be necessary to encourage work at an older age. Policy response in EU to challenges of ageing became 'active ageing'. The new emphasis on employment in later life has been the main reason for the recent interest in active ageing and the fact that it has become a political priority in Europe [4]. Increasing the employment rate of older workers became a centerpiece in the employment strategy agreed upon by the Lisbon summit. The goal set in 2000 for the year 2010, to be achieved by all member states, was an employment rate of at least 50\% among the population aged 55-64. In 2010 European Council declared the year 2012 as the European Year of Active Ageing and Solidarity between the Generations, with the goal of raising awareness of the contribution that older people make to society and encouraging policymakers and relevant stakeholders at all levels to take action to create better opportunities for active ageing. The 2012 Commission Communication 'Towards a job rich recovery' also emphasized the importance of introducing comprehensive measures to help extend working lives, such as tax-benefit incentives, access to lifelong learning through career guidance and training, flexible working arrangements for those who need them, and safe and healthy workplaces [5].

The main directions of pension reforms were as follows: rising retirement ages, increasing contribution years for entitlement, Eliminating or restricting early retirement options, introducing incentives for later retirement, changing indexation rules from wages to prices, extending the working period for the calculation of benefits to the entire working life, adjusting benefits to changes in life expectancy, adjusting eligibility conditions to changes in life expectancy [6]. Policy action towards prolonging work life include changes in benefits parameters for the older unemployed, reduced unemployment benefits for older persons, reduction in the duration of unemployment benefits, abolition of the job search exemption for the older unemployed, more activation during unemployment. All these measures strengthened incentives to continue working at an older age [7].

The governments implement policy measures not only towards older workers, but also towards the employers, providing them benefits for employing and training employees aged $50+$. The German government has, for example, implemented a new policy package called 'Campaign 50 Plus', which provides wage subsidies to employers who employ people over 
50 and assists in the retraining of such workers. In the Netherlands, employment policy promotes part-time jobs as a means of expanding job opportunities, including opportunities for older people. It is apparent from such examples that European countries have begun moving towards the promotion of employment for older people. On the other hand, the US government has had a policy of promoting the employment of older people for several decades. It introduced the Age Discrimination in Employment Act. This law was first enacted in 1967 and then revised in 1978 and 1986. It first aimed at eliminating age discrimination against people up to 65 . The age limit was raised to 70 in the first revision, and then lifted altogether in the second revision. This has created an employment environment where there is no mandatory retirement or age limit for hiring, with a few exceptions [8].

Although active ageing is a common policy paradigm in the EU countries, some of them have significantly higher rates of older workers employment.

The main stages of the research are aimed at revealing the leading countries in attracting older workers to the labor market:

- $\quad$ ranking the countries according to the older workers' capability to implement their professional qualities at the labor market on a global scale,

- ranking OECD countries by employment level of older workers,

- $\quad$ ranking countries by duration of working life at European level.

\section{Data and methods}

The research is based on the information sources of different scales: the global, supranational and national ones. The global level includes the Global Age Watch Index reports provided by Help Age International [9-11] and the Golden Age Index Report provided by Price Waterhouse Coopers [12,13]. Eurostat data regarding duration of working life is used for supranational level analysis [14]. A country is used as a taxonomic unit of analysis. Ranking the leading and outsider countries is carried out by means of extreme value's repeatability analysis. An object of the study is resources' replenishment at the national labor market. The subject of the study is involving older workers to the national labor market.

The global level is represented by 91-96 countries for the period of 2013-2015. The countries are divided into two groups - leaders and outsiders. The leaders are chosen by the maximum value of the "overall index rank". The outsiders are the countries with the minimal value of the indicator. Countries of each group are presented by "overall index value", "capability rank" and "capability value". In addition, the "average values for a group of countries" are calculated. The set of indicators allows ranking countries by the efficiency of the state policy towards attracting older workers to the labor market.

The supranational level is represented by the two categories of countries. The countries of the first category are OECD developed economies. 35 OECD countries are ranked to two groups for period 2014-2016. The first group is represented by five counties with the maximal values of the Golden Age Index. The second one includes five countries with the minimal values of the Golden Age Index. The values of the indicator "average values for a group of countries" are also calculated for these countries. The EU countries represent the second category of the supranational. 35 EU countries are ranked to two groups: the leaders and the outsiders by the maximum and minimal values of the indicator "duration of the working life" in 2016-2018. In addition, the indicator «average chain growth rate over the period» is calculated.

All the indicators presented and calculated are aimed at ranking countries according to the state policy efficiency in the domain of prolonging older workers' stay at labour market. 
Choosing the leaders provides an opportunity for further research in investigation of their good practices in older workers policy.

\section{Results}

\subsection{Ranking the countries according to the older workers' capability to implement their professional qualities at the labor market on a global scale}

The Global Age Watch Index (GAWI) characterizes state policy regarding older people at the global level. It is calculated from 2013 and now the data for 2013, 2014 and 2015 years is available. The popularity of GAWI is increasing. In 2013 the Index covered 91 countries, while in 2014-2015 their number increased to 96. The aim of GAWI is to access the quality of life and wellbeing of older people. It highlights the successes and fails in the state policy and responses to the global ageing challenges. Also, it stimulates demand for and supply of sufficient age- and sex-disaggregated data as necessary to study policy-relevant topics on ageing [5].

GAWI is characterized by the following indicators: $O I R_{i}^{c o d}$ - overall index rank; $O I V_{i}^{\text {cod }}$ - overall index value. The upper index of the indicator represents ISO country code [11], the bottom index marks the last two figures of the year.

GAWI includes four domains, representing country ranks in different spheres. Capability domain (IC) highlights the opportunities of older workers to access to the labor market their employment levels, and educational attainment of older people. Employment level of people aged 55-64 shows their opportunities at labor market. Educational attainment shows their human and social capital potential. Capabilities' domain is characterized by the

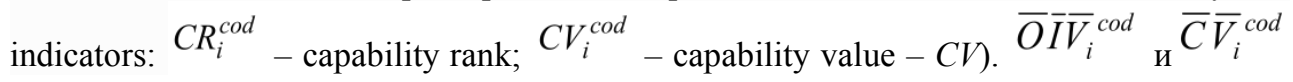
- average values for a group of countries. Comparing $C R_{i}^{\text {cod }}$ and $O I R_{i}^{c o d}, C V_{i}^{\text {cod }}$ and $O I V_{i}^{\text {cod }}$ the dynamics of the above said indicators for the period of 2013-2015 [3,4]. 
Table 1. Dynamics of $C R_{i}^{c o d}$ and $C V_{i}^{c o d}, O I R_{i}^{c o d}$ and $O I V_{i}^{c o d}$ during 2013-2015.

\begin{tabular}{|c|c|c|c|c|c|c|c|c|c|c|c|c|c|c|}
\hline & & 2013 & & & & & 2014 & & & & & 2015 & & \\
\hline & & & & & leading $\mathrm{c}$ & untries ac & ccordin & ig to $C l$ & $R_{i}^{c o d}$ & alue & & & & \\
\hline 言 & $C R_{13}^{\mathrm{kp}}$ & $C V_{13}^{K p}$ & $O I R_{13}^{\mathrm{Rp}}$ & $O I V_{13}^{\mathrm{Kp}}$ & 竎 & $C R_{14}^{\mathrm{kp}}$ & $C V_{14}^{\mathrm{Kp}}$ & $\left|O I R_{14}^{\mathrm{KT}}\right|$ & $O I V_{14}^{\mathrm{kp}}$ & 音 & $C R_{15}^{\mathrm{Kp}}$ & $C V_{15}^{\mathrm{kp}}$ & $O I R_{15}^{\mathrm{Kp}}$ & $O I V_{15}^{\mathrm{kp}}$ \\
\hline $\mathrm{NO}$ & 1 & 85.4 & 2 & 89.8 & $\mathrm{NO}$ & 1 & 76.2 & 1 & 93.4 & $\mathrm{NO}$ & 1 & 76.3 & 2 & 89.3 \\
\hline US & 2 & 76.6 & 8 & 83.8 & $\mathrm{AU}$ & 2 & 70.2 & 13 & 76.1 & $\mathrm{CH}$ & 2 & 75.0 & 1 & 90.1 \\
\hline AM & 3 & 76.5 & 51 & 50.5 & SE & 3 & 65.7 & 2 & 88.3 & $\mathrm{DE}$ & 3 & 68.4 & 4 & 84.3 \\
\hline $\mathrm{AU}$ & 4 & 76.3 & 11 & 79.8 & US & 4 & 65.0 & 8 & 83.5 & US & 4 & 65.7 & 9 & 79.3 \\
\hline SE & 5 & 74.3 & 1 & 89.9 & DE & 5 & 62.8 & 5 & 86.3 & SE & 5 & 65.6 & 3 & 84.4 \\
\hline $\bar{C} \bar{V}_{20}^{c o}$ & $=77.8$ & $\bar{O} \bar{I}$ & $\bar{V}_{2013}^{c o d}$ & $=78.76$ & $\bar{C} \bar{V}_{201}^{c o c}$ & $=67.98$ & $\bar{O} \bar{I}$ & $\bar{V}_{2014}^{c o d}$ & $=85.52$ & $\bar{C} \bar{V}_{201}^{c o s}$ & $=70.2$ & $\bar{O} \bar{I} \bar{I}$ & $\bar{V}_{2015}^{c o d}$ & 85.48 \\
\hline & & & & & utsider co & tries acc & cording & & ${ }_{i}^{c o d}{ }^{c o d}$ & & & & & \\
\hline JO & 91 & 1.6 & 88 & 11.4 & PS & 96 & \begin{tabular}{|l|l|} 
\\
\end{tabular} & \begin{tabular}{|l|}
94 \\
\end{tabular} & 4.5 & PS & 96 & 1.8 & 93 & 12.3 \\
\hline $\mathrm{RW}$ & 90 & 5.3 & 87 & 16.6 & JO & 95 & 1.6 & 90 & 17.0 & $\mathrm{JO}$ & 95 & 4.4 & 85 & 28.6 \\
\hline MZ & 89 & 6.7 & 83 & 25.5 & $\mathrm{MZ}$ & 94 & 4.2 & 95 & 4.1 & MZ & 94 & 4.5 & 94 & 4.5 \\
\hline $\mathrm{TZ}$ & 88 & 7.3 & 90 & 4.6 & TR & 93 & 6.0 & 77 & 36.1 & TR & 93 & 7.0 & 75 & 36.3 \\
\hline $\mathrm{AF}$ & 87 & 9.4 & 91 & 3.3 & RS & 92 & 9.9 & 78 & 35.4 & IQ & 92 & 11.9 & 87 & 23.2 \\
\hline $\bar{C} \bar{V}_{201}^{c o}$ & 6.06 & $\bar{O} \bar{I}$ & $\overline{V_{2}} c o d 3$ & $=12.28$ & $\bar{C} \bar{V}_{20}^{c c}$ & $=4.6$ & $\bar{O} \bar{I} \bar{V}$ & $\begin{array}{c}c o d \\
2014\end{array}$ & $=19.42$ & $\bar{C} \bar{V}_{201}^{c o l}$ & $=5.92$ & $\bar{O} \bar{I}$ & $\overline{V_{2015}^{c o d}}$ & $=20.98$ \\
\hline & & & & & & Other & countri & & & & & & & \\
\hline UA & 35 & 48.7 & 66 & 40.2 & UA & \begin{tabular}{|l|}
85 \\
\end{tabular} & \begin{tabular}{|l|}
15.2 \\
\end{tabular} & 82 & 31.0 & UA & 44 & 34.8 & 73 & 37.0 \\
\hline $\mathrm{CZ}$ & 22 & 54.2 & 25 & 62.5 & $\mathrm{CZ}$ & 28 & 44.5 & 25 & 64.8 & $\mathrm{CZ}$ & 17 & 56.2 & 22 & 65.6 \\
\hline
\end{tabular}

Source: Own processing.

Change in the leaders' group composition shown in the Table1 demonstrates the activity and discretion in the IC domain development. Leaving the leaders' group by Armenia (AM) in 2014 and Australia (AU) is explained by $C R_{2013}^{A M}>I R_{2013}^{A M}$ (significant difference) and $C R_{2014}^{A U}>O_{2014}^{A U}$ respectively. IC domain is a part of $G A W I$, which explains the arrival of Germany (DE) in the group in 2014 with $C R_{2014}^{D E} O I R_{2014}^{D E}$. In 2015 Switzerland entered the leaders' group. It has $C R_{2015}^{C H} 2$, a $O I R_{2015}^{C H}=1$. The domains of GAWI are interrelated and mutually conditioned. So, the difference between $C V_{i}^{\text {cod }}$ and $O I V_{i}^{\text {cod }}$ should be rather small. Presence of Norway (NO), USA (US) and Switzerland (SE) in the group during three years proves: 1) the relative stability of $I C$, while the value of $C V_{i}^{c o d}$ doesn't form simultaneously but during long-term period; 2 ) the relative volatility of $I C$, while the values of countries' values change annually. For example, Switzerland changed the values of $C R_{i}^{c o d}$ and $O I R_{i}^{c o d}$ each year, wherein stayed in the group. Two circumstances characterize the leaders' group in general. Firstly, the European presence is rising. In 2013 2 countries, in $2014-3$ countries and 4 countries in 2015 were the European ones among the 5 leaders. Secondly, IC domain decreases the value of overall GAWI rank: in 2013 the values of $\bar{C} \bar{V}_{2013}^{\text {cod }}$ and $\bar{O} \bar{I} \bar{V}_{2013}^{\text {cod }}$ differed insignificantly, in 2014 and 2015 their difference was considerable. The synthesis of circumstances determines the regional aspect of the possibility of working longer for older workers. 
The composition of outsiders' group was changing each year. Jordan (JO) and Mozambique (MZ) were present in the group during three years. Rwanda (RW), Tanzania (TZ) and Afghanistan (AF) left the group in 2014 and were replaced by Palestine (PS), Turkey (TR) and Serbia (RS). In 2015 Serbia was replaced by Iraq (IQ). A distinguishing feature of the outsiders' group is absence of the state policy towards older workers' employment. Thus, Tanzania's rank was 86, Ukraine's (UA) was 85. Ukraine differs from other countries in the group by significant volatility of $C R_{i}^{c o d}$ : in 2013 its rank was 35, in 2015 - 44. This fluctuation points to the absence of consistent state policy towards older workers. The opposite situation is in Czech Republic (CZ), where fluctuations of $C R_{i}^{c o d}$ and $C V_{i}^{c o d}$ are insignificant, which testifies the existence of consistent policy towards older people's employment.

\subsection{Ranking OECD countries by older workers' employment rate}

Golden Age Index is calculated annually by PWC for OECD countries ( $\left.{ }^{G A I_{i}^{c o d}}\right)$. It is calculated on the basis of labor market indicators and weighted by their significance: employment rate of aged 55-64 (40\%); employment rate of aged 65-69 (20\%); gender gap in employment (ration women/men) (10\%); incidence of part-time work for 55-64 (10\%); full-time earnings, 55-64 relative to 25-54 (ratio) (5\%); average effective labor force exit age (years) (5\%); participation in training of 55-64 age group (ratio, relative to employed persons aged 25-54) (5\%) [6]. The maximal index score is 100. Table 2 shows the dynamics of $G A I_{i}^{c o d}$ indicator for the leading and outsider countries in 2014-2016 [6, 7].

Table 2. Dynamics of leading and outsider countries by $G A I_{i}^{\text {cod }}$

\begin{tabular}{|c|c|c|c|c|c|}
\hline \multicolumn{2}{|c|}{2014} & \multicolumn{2}{|c|}{2015} & \multicolumn{2}{|c|}{2016} \\
\hline \multicolumn{6}{|c|}{ The leading countries according to $G A I_{i}^{c o d}$ value } \\
\hline Country & $G A I_{i}^{c o d}$ & Country & $G A I_{i}^{c o d}$ & Country & $G A I_{i}^{c o d}$ \\
\hline IS & $\begin{array}{l}97.2 \\
\end{array}$ & IS & $\begin{array}{l}99.5 \\
\end{array}$ & IS & 998.7 \\
\hline $\mathrm{NZ}$ & 82.4 & $\mathrm{NZ}$ & 84.7 & $\mathrm{NZ}$ & 85.3 \\
\hline IL & 78.3 & IL & 80.6 & IL & 82.3 \\
\hline $\mathrm{SE}$ & 78.2 & SE & 80.1 & ES & 81.8 \\
\hline ES & 76.5 & ES & 78.8 & SE & 81.2 \\
\hline \multicolumn{6}{|c|}{ Outsider countries according to $G A I_{i}^{c o d}$ value } \\
\hline TR & 37.8 & TR & 36.5 & TR & 38.4 \\
\hline LU & 43.2 & LU & 41.3 & LU & 38.8 \\
\hline SI & 41.9 & SI & 44.7 & SI & 48.2 \\
\hline GR & 42.0 & GR & 46.4 & GR & 48.9 \\
\hline $\mathrm{BE}$ & 45.4 & $\mathrm{BE}$ & 47.7 & $\mathrm{BE}$ & 49.6 \\
\hline
\end{tabular}

Source: Own processing.

Statistical sample $G A I_{i}^{\text {cod }}$ shown in the Table 2 is quantitatively and qualitatively different from GAWI sample. The quantity of countries is three times as less. They are more homogeneous while the majority represents developed countries with high per capita income and high ranks of Human Development Index. So, the composition of the leaders' and outsiders' groups was unchanging as also their ranks. The majority of leaders' group is represented by the European countries Iceland (IS), Sweden (SE) and Spain (ES). New 
Zealand (NZ) and Israel (IL) thought to be the benchmark countries regarding attitude towards older people. The values of $G A I_{i}^{c o d}$ for all countries of the group were rising in 2015 and 2016, which implies the existence of a targeted policy.

The outsiders' group includes only the European countries. Turkey (TR) (outsider by $C R_{i}^{c o d}$ in 2014 and 2015), Slovenia (SI) and Greece (GR) represent Balkan Peninsula. The values of $G A I_{i}^{c o d}$ for Balkan countries have risen. Presence of Belgium (BE) and Luxemburg (LU) in the group allows supposing, that there could be several reasons for absence of the state productive ageing policy. Some countries have no resources to tackle the problem of ageing. The other countries do not have a problem and therefore do not need special state programs. The values of $G A I_{i}^{L U}$ in 2015 and 2016 were decreasing, the values of $G A I_{i}^{B E}$ were rising, which proves the existence of different initial conditions in developed countries.

\subsection{Ranking countries by duration of the working life}

The EU countries carry out common policy of labor market. Indicator $D W L_{i}^{c o d}-$ «duration of the working life» characterizes labor relations [8]. Eurostat data of $D W L_{i}^{c o d}$ for the period of 2008-2018 allows to reveal dynamics' tendencies of $D W L_{i}^{c o d}$ by means of indicators «average chain growth rate over the period» $D W L_{i}^{c o d}\left({ }_{T_{n p}}^{\text {л }} D W L_{i}^{\text {cod }}\right)$ and «basic growth rate for the period» $D W L_{i}^{c o d}\left(T_{n p}^{\sigma} D W L_{i}^{c o d}\right)$. Data in Table 3 shows dynamics of five countries with minimal and maximal values of $D W L_{i}^{\text {cod }}$ for the period 2016-2018, and also $\bar{T}_{n p}^{\text {л }} D W L_{i}^{\text {cod }}$ and $T_{n p}^{\sigma} D W L_{i}^{\text {cod }}$ for countries with extremal values of $D W L_{i}^{\text {cod }}$ in 2018.

Table 3. Dynamics of working life duration

\begin{tabular}{|c|c|c|c|c|c|c|c|}
\hline \multicolumn{2}{|c|}{2016} & \multicolumn{2}{|c|}{2017} & \multicolumn{2}{|c|}{2018} & \multicolumn{2}{|c|}{ For the period } \\
\hline Country & $D W L_{i}^{c o d}$ & Country & $D W L_{i}^{c o d}$ & Country & $D W L_{i}^{c o d}$ & $\bar{T}_{n p}^{\text {л }} D W L_{i}^{c o d}$ & $T_{n p}^{\sigma} D W L_{i}^{c o d}$ \\
\hline \multicolumn{8}{|c|}{ Countries with the longest duration of the working life } \\
\hline IS & 47.4 & IS & 47.0 & IS & 46.3 & $\begin{array}{l}0.50 \\
\end{array}$ & 4.51 \\
\hline $\mathrm{CH}$ & 42.4 & $\mathrm{CH}$ & 42.5 & $\mathrm{CH}$ & 42.7 & 0.35 & 3.14 \\
\hline SE & 41.3 & $\mathrm{SE}$ & 41.7 & SE & 41.9 & 0.57 & 5.28 \\
\hline DK & 40.3 & NL & 40.1 & NL & 40.5 & 0.03 & 0.25 \\
\hline NL & 39.9 & \multirow{2}{*}{\multicolumn{2}{|c|}{\begin{tabular}{|l|c|} 
DK & 39.7 \\
$\bar{D} \overline{W L}$ & $c o d$ \\
2017 & $=42.20$ \\
\end{tabular}}} & DK & 39.9 & 0.42 & 3.85 \\
\hline $\bar{D} \overline{W L_{201}^{c o c}}$ & $\begin{array}{l}l \\
l 6=42.26\end{array}$ & & & \multicolumn{2}{|c|}{$\bar{D} \overline{W L}_{2018}^{c o d}=42.26$} & & \\
\hline \multicolumn{8}{|c|}{ Countries with the shortest duration of the working life } \\
\hline TR & 28.5 & TR & 29.0 & TR & 29.4 & 1.78 & 17.13 \\
\hline MK & 31.0 & ME & 31.2 & MK & 31.5 & 0.22 & 1.94 \\
\hline ME & 31.2 & MK & 31.3 & IT & 31.8 & 2.04 & 15.11 \\
\hline IT & 31.3 & IT & 31.7 & ME & 32.0 & 0.77 & 7.07 \\
\hline $\mathrm{BG}$ & 31.7 & GR & 32.5 & GR & 32.4 & 0.22 & 1.89 \\
\hline $\bar{D} \overline{W L_{201}^{c o c}}$ & $=30.74$ & \multicolumn{2}{|c|}{$\bar{D} \overline{W L}_{2017}^{c o d}=31.14$} & \multicolumn{2}{|c|}{$\bar{D} \overline{W L} \bar{L}_{2018}^{c o d}=31.42$} & & \\
\hline
\end{tabular}

Source: Own processing. 
The essence of $D W L_{i}^{c o d}$ excludes the opportunity of significant changes in its values, which explains stability in group composition in Table 3. The majority of countries with long working life comes from Northern Europe (northern group). All countries with short seniority come from South (southern group). Geographic orientation of the extreme values of $D W L_{i}^{c o d}$ is probably explained by the official retirement age fixed by law. At the same time, it is more difficult for people of pre-retirement age to find job than for the younger ones. Therefore, retirement age doesn't determine the durability of working life directly. A methodology of seniority calculation is also different in countries, which also explains how countries enter the table groups.

Seniority is a result of the desires and opportunities of the parties to build employment relations. Productive ageing policy, conducted by the government, contains mechanisms and tools aimed to convince the parties to reach a compromise for their interests' sake. It is possible that in civil society the employers and the older workers can realize the necessity of compromise in labor relations on their own. This may explain the absence of Switzerland $(\mathrm{CH})$, Denmark (DK) and Netherlands (NL) in the table 2 and presence in the northern group.

Decrease in values of $D W L_{2017}^{I S}$ and $D W L_{2018}^{I S}$ implies the existence of the upper limit of working life duration in Iceland (IS). The values of $\bar{T}_{n p}^{\text {л } D W L_{i}^{c o d}}$ and $T_{n p}^{\sigma} D W L_{i}^{\text {cod }}$ for northern group countries demonstrate a slowdown in the pace of dynamics, which also argues for the existence of an upper limit of seniority. Not slowdown but suspension of growth of $D W L_{i}^{\text {cod }}$ in the northern group justify the equality $\bar{D} \overline{W L}_{2016}^{\text {cod }} \approx \bar{D} \overline{W L} \bar{L}_{2017}^{\text {cod }}$, $\bar{D} \overline{W L}_{2016}^{c o d}=\bar{D} \overline{W L}_{2018}^{c o d}$. Growth rates of the southern group are increasing $\left(\bar{D} \overline{W L}_{2016}^{c o d}<\right.$ $\bar{D} \overline{W L}_{2017}^{c o d}<\bar{D} \overline{W L}_{2018}^{c o d}$ ), which proves the mobility of the bottom line of $D W L_{i}^{c o d}$.

\section{Discussion and Conclusion}

1. Use of $I C$ (capability) domain of the $G A W I$ on a global scale allowed to reveal the extreme values (5 maximum and 5 minimal ones) of $C V_{i}^{c o d}$. Dynamics of extrema of $C V_{i}^{c o d}$ for 2013-2015 demonstrated individual stability (composition of countries in a group) and collective stability $\left(\bar{C} \bar{V}_{i}^{\text {cod }}\right)$. Maximal values of $\bar{C} \bar{V}_{i}^{\text {cod }}$ were as follows: 2013. - 77.82, 2014 - 67.98, 2015. - 70.20. Minimal values of $\bar{C} \bar{V}_{i}^{\text {cod }}$ were equal to: $2013-6.06,2014-4.60,2015$-5.92. The average maximal value of $\bar{C} \bar{V}_{i}^{\text {cod }}$ in 2013 was 12.84 times as higher as the average minimal value of $\bar{C} \bar{V}_{i}^{\text {cod }}$, in $2014-14.77$ times and 2015 - 11.85 times (Table 1). A significant difference can be explained by the essence of the IC domain - the opportunity for older people to find job in the labor market. Demand for older workers arises due to the unfavorable demographic situation in the country and the inability (unwillingness) to import labor force. In case of favorable demographic situation, the state pursues a policy unfavorable for the work of retirees. The policy of "giving way to the young" is implemented in case of chronic unemployment caused by low level of economic development. For example, many retirees resigned in Ukraine in 2012 and 2013 when an income tax was imposed on retirement benefits for working pensioners. Therefore, 
the domain does not have any common sense in several countries while there is no need to involve older persons into work.

2. Indices and rankings are a worldwide recognition of the ability of public authorities to convince labor market actors in the necessity for cooperation, which enables successful implementation of policy aimed at tackling aging. Calculation of $G_{i}^{\text {cod }}$ for OECD countries is important while this organization is a worldwide recognized platform for discussions on the most pressing issues, including older workers to the labor market. Values of $G A I_{i}^{c o d}$ are the part of the analytical foundation for discussions and formal agreements between OECD countries. For example, a report by Price Waterhouse Coopers on the UK Economic Outlook. Section 4.2 discusses the updated results for Youth Employment and Golden Age indices [12]. At the same time, the values of $G A I_{i}^{c o d}$ are the result of a common policy implemented by national institutions in the framework of formal intergovernmental agreements. An example is a dynamics of $\overline{G A} \bar{I}_{i}^{\text {cod }}$ in both groups of countries: the values of $\overline{G A} \bar{I}_{i}^{c o d}$ was increasing annually at the same pace in each group (Table 2). The collection and analysis of information, collective discussions of ways and forms of development, the adoption of joint agreements make the OECD policy effective. Governments' mutual learning, multilateral surveillance and appropriate pressure are the most effective OECD tools. However, despite the OECD common policy, each country chooses its own methods and forms of its implementation. The government of a particular country takes into account demographic and economic situation, national traditions and perceptions in society. Assignment of countries in Table 2 to one or another group in no way divides them into the "positive" or "negative" ones.

3. An employee's seniority is the duration of his relationship with the employer. The duration of the relationship demonstrates, on the one hand, the employee's interest in realizing his professional qualifications, and demand for his qualities in the labor market on the other hand. The average duration of working life in country ( $\left.D W L_{i}^{c o d}\right)$ characterizes the extent of mutual trust in employee-employer relationship at the national labor market. State policy of productive ageing is directed at an increase of the value of $D W L_{i}^{c o d}$. So, dynamics direction of $D W L_{i}^{c o d}$ shows the effectiveness of productive ageing policy. Extreme values of $D W L_{i}^{c o d}$ shows the extreme displays of mutual loyalty of employers and employees. Countries with maximum loyalty (northern group) have high value of $O I R_{i}^{c o d}$. For example, in 2015. Iceland took the $7^{\text {th }}$ rank, Switzerland $-1^{\text {st }}$ rank, Sweden $-3 \mathrm{rd}$, Netherlands -6 th, Denmark - 11th. This means that countries also had high ranks in other domains: «Income security» (Measured by pension coverage, poverty rate in old age, the relative welfare of older people, and living standards using GNI per capita as a proxy), «Health status» (Measured by three indicators: life expectancy at 60, healthy life expectancy at 60 , and psychological wellbeing. Good physical and mental health is critical to social and economic engagement of older people), «Enabling environment» (Measured by access to public transport, physical safety, social connections and civic freedom). Therefore, duration of the working life is a complex result of older people wellbeing. While average value of $\bar{T}_{n p}^{\text {л }} D W L_{i}^{\text {cod }}$ for northern group of countries was 0.37 , its value for countries of the southern group was 1.006. This means that growth rate of the southern group is 2.72 times higher than the rate of the northern one. Average value of $T_{n p}^{\sigma} D W L_{i}^{c o d}$ 
in northern group was equal to 3.406, southern group has 8.63. Relatively low growth rates of $D W L_{i}^{\text {cod }}$ in northern group and relatively high ones in the southern group prove shrinking the gap between groups. The difference between $\bar{D} \overline{W L}{ }_{2016}^{\text {cod }}$ for the southern and northern group was $37.48 \%$, for $\bar{D} \overline{W L}_{2017}^{c o d}-35.52 \%$, for $\bar{D} \overline{W L}_{2018}^{c o d}-34.50 \%$. Reducing difference between the groups is a sign of the common policy in the EU countries. In no way does, duration of working life determines the country level of socio-economic development.

\section{References}

1. D. Bloom, D. Canning, G. Fink, Implications of Population Ageing for Economic Growth. Oxford Review of Economic Policy, 26(4), 583-612 (2010)

2. S. Harper, Economic and Social Implications of Aging Societies. Science, 346(6209), 587-591 (2014)

3. OECD, Pensions at a glance 2017: OECD and G20 indicators, Paris: OECD Publishing (2017)

4. A. Walker, T. Maltby, Active ageing: A strategic policy solution to demographic ageing in the European Union. International Journal of Social Welfare, 21(1) (2012)

5. T. Feifs, T. Weber, O. Vargas Llave, K. Fric, M. Curtarelli, I. Mandl, Role of Governments and Social Partners in Keeping Older Workers in the Labour Market. Eurofound, Dublin (2013)

6. M. Kohli, C. Arza, The Political Economy of Pension Reform in Europe. In: $R$. $H$. Binstock, \& L. K. George (Eds.), Handbook of aging and the social sciences, 251-264 (2011)

7. A. Sonnet, H. Olsen, T. Manfredi, Towards More Inclusive Ageing and Employment Policies: The Lessons from France. De Economist, 162, 315-339 (2014)

8. A. Seike, Pensions and Labour Market Reforms for the Ageing Society. In: Eds. $H$. Conad, V. Heindorf, F. Waldenberger, Human Resource Management in Ageing Society, 29-42 (2008)

9. HelpAge International, Global AgeWatch Index 2013: Insight report (2013)

10. HelpAge International, Global AgeWatch Index 2014: Insight report (2014)

11. HelpAge International, Global AgeWatch Index 2015: Insight report (2015)

12. PWC. PWC Golden Age Index. The potential \$2 trillion prize from longer working lives [online], Available at: https://www.pwc.co.uk/economic-services/goldenage/pwc-golden-age-index-june2017-final-v2.pdf(2017)

13. PWC. PWC Golden Age Index. Unlocking a potential $\$ 3.5$ trillion prize from longer working lives [online], Available at: https://www.pwc.co.uk/economicservices/golden-age/golden-age-index-2018-final-sanitised.pdf(2018)

14. Eurostat. Duration of working life, Annual data [online], Available at: https://appsso.eurostat.ec.europa.eu/nui/show.do?dataset=lfsi_dwl_a\&lang=en (2019) 